\title{
A inteligência possível do século xxI
}

\section{RESUMO}

$\mathrm{O}$ autor pensa que um dos principais problemas que se coloca aos intelectuais do século XXI é o de encontrar as melhores maneiras de explorar o serviço de inteligência coletiva, o desenvolvimento desta imensa memória comum e esta nova potência de análise e de simulação oferecida pelo cálculo automático. “É um novo problema, o da inteligência possível, que não foi colocado para qualquer geração antes da nossa", escreve Lévy.

\section{PALAVRAS-CHAVE}

- ciberespaço

- filosofia

- comunicação

\section{ABSTRACT}

The author thinks that one of the main problems that faces intellectuals of the $21^{\text {st }}$ century is that of finding the best ways of exploring the service of collective intelligence as well as the development of this huge common memory and this new analysis power of analysis simulation offered by an automatic calculation. "It is a new problem, the one of the possible intelligence, that was not faced by other generations that came before ours", writes Léry.

\section{KEY WORDS}

cyberspace

- philosophy

- communication

\section{"Q} ual é a responsabilidade dos intelectuais face às novas tecnologias de comunicação?". Esta é a questão que eu gostaria de tentar responder neste texto, seguindo, assim, uma solicitação dos organizadores de um colóquio em Tóquio sobre os intelectuais no século XXI.

Filosoficamente falando, eu começaria, na primeira parte, por definir a identidade e a função dos intelectuais. Para fazer isso, eu lembraria, antes, que as comunidades humanas só podem viver juntas se compartilharem um certo número de sistemas simbólicos, tais como: línguas, escritas, disciplinas de conhecimento, tradições técnicas e profissionais, convenções estéticas, instituições políticas, normas religiosas e jurídicas etc. A "cultura" destes sistemas simbólicos distingue a espécie humana das outras espécies de animais sociais que povoam nosso planeta. A partir desta constatação, eu defenderia a idéia de que o papel principal dos intelectuais, em todas as culturas, inclusive a cultura mundial da emergente inteligência coletiva, é o de estudar os sistemas simbólicos com que as comunidades humanas vivem em simbiose e de preservar sua articulação, seu bom andamento e seu aperfeiçoamento. Segundo esta definição, os intelectuais contemporâneos se agrupam, principalmente, em três categorias, cada vez mais chamadas a trabalharem conjuntamente: os pesquisadores em ciências humanas e sociais, os pesquisadores em ciências e técnicas de informação e os responsáveis pela transmissão das heranças culturais. Ora, neste começo de século, os intelectuais se deparam com o início de uma mutação cultural de grande amplitude. A maioria dos produtos e dos procedimentos simbólicos da humanidade é digitalizada ou, ao menos, representada por documentos digitais, e disponível on-line sob a forma de textos, imagens, sons, músicas e equipamentos variados. Além disso, nós já dispomos de uma miríade de automatismos manipuladores de símbolos capazes de se coordenarem em rede para filtrar, interpretar e transformar, à vontade, os dados digitais. Um dos principais problemas que se coloca aos intelectuais do século XXI é, pois, o de encontrar as melhores maneiras de explorar o serviço de inteligência coletiva, o desenvolvimento desta imensa memória comum e esta nova potência de análise e de simulação oferecida pelo cálculo automático. Trata-se de um problema novo, o da inteligência possível, que não foi colocado para qualquer geração antes da nossa.

A digitalização dos documentos, sua interconexão em um espaço virtual ubiqüitário e as possibilidades de tratamento destes documentos anunciam uma mutação cultural de grande amplitude, que se desenvolverá, principalmente, nas próximas gera-

\section{Pierre Lévy}

Universidade de Ottawa 
ções. Mais do que assistir de fora esta mutação, os intelectuais devem, na minha opinião, tomar a dianteira. Na verdade, a informática, que se pode definir, simplesmente, como a arte e a ciência da construção de automatismos manipuladores de símbolos, encontra-se, ainda, na pré-história neste início do século XXI. A comunidade dos pesquisadores em ciências humanas, qualquer que seja a diversidade de suas disciplinas e de suas raízes culturais, pode fazer com que a informática nascente se beneficie pela compreensão dos processos simbólicos e das tradições multisseculares de reflexão sobre o sentido e a sua complexidade. Essa comunidade contribuiria, assim, para o nascimento de uma informática de cunho semântico a serviço de uma nova inteligência possível, capaz não apenas de automatizar as operações aritméticas e lógicas, mas também de um leque indefinidamente aberto de procedimentos hermenêuticos que permitam dar sentido à memória coletiva.

Na segunda parte deste texto, eu apresentarei um programa de pesquisa que tem por objetivo desenvolver a inteligência possível nesse sentido que dei anteriormente. Sob um ponto de vista técnico, este programa pode ser dividido em duas partes. Primeiramente, eu irei expor os princípios de base de uma codificação semântica universal da memória digital. Em segundo lugar, eu irei evocar a programação dos automatismos semânticos capazes de efetuar sobre o código semântico operações intelectuais muito mais complexas e sutis do que as que são acessíveis pelos equipamentos comuns.

A codificação semântica, que constitui a peça central do dispositivo, tem duas finalidades principais:

a. ultrapassar a multiplicidade de línguas naturais e a incompatibilidade dos diversos sistemas de classificação em uso

b. preparar e facilitar as performances dos automatismos semânticos.

Sob o viés filosófico, a perspectiva geral da inteligência possível é a de uma compatibilidade e de uma computabilidade universal que deixa o campo livre à abertura indefinida da diversidade semântica. O código semântico permite a representação científica do universo simbólico humano sob a forma de um cosmos matematicamente explorável, um espaço-tempo intelectual virtualmente infinito. Ao compartilharem o espaço-tempo semântico coordenado pela inteligência possível de suporte informatizado, as diversas comunidades humanas poderiam fazer evoluir os grupos de automatismos adaptados aos trabalhos intelectuais sobre a memória em rede que elas julgassem ser os mais pertinentes, de acordo com a diversidade de suas finalidades e de seus critérios particulares.

\section{0 intelecto e seus intelectuais: a consciência crítica}

Há várias definições possíveis de um intelectual. Uma delas é mais estreita, limitada a uma certa zona cultural e histórica, enquanto a outra, de minha preferência, faz da função intelectual uma dimensão universal de toda a cultura.

Segundo a definição usual, os intelectuais são uma categoria particular de pensadores e de escritores que intervêm ativamente nas questões públicas. Eles aparecem na Europa durante a época das Luzes, no momento em que a opinião pública - que se expressa na imprensa - se encontra em desaceleração pela sociabilidade urbana. O papel desta categoria social na formação da consciência coletiva aumenta nos séculos XIX e XX, paralelamente às profundas transformações das sociedades européias, depois mundiais, por causa da Revolução Industrial, da urbanização e do desenvolvimento das comunicações de massa. Os intelectuais encabeçaram ou se tornaram os porta-vozes dos movimentos sociais, revolucionários, socialistas, fascistas, nacionalistas, democráticos e outros que sacudiram a vida pública nos três últimos séculos. Às vezes politicamente engajados, atacando ou incensando os poderes políticos, as estruturas econômicas, as tradições culturais ou as evoluções da civilização em curso, os intelectuais se consideram, freqüentemente, como os portadores da consciência crítica, senão da consciência moral (herdeiros, nisso, da função clerical), das sociedades das quais são egressos. Respeitados por suas realizações artísticas, literárias ou filosóficas, suas intervenções no campo midiático, relativamente circunscrito, podiam ter um peso considerável. Mas, desde o desenvolvimento acelerado das mídias e das redes eletrônicas no último quarto do século $\mathrm{XX}$, e, mais ainda, desde a explosão do ciberespaço por volta do ano 2000, que, pelo contrário, o efeito foi o de dar a palavra a todo mundo (ou quase). Assim, a voz dos intelectuais parece, cada vez mais, difícil de se fazer ouvir e, talvez, cada vez menos necessária com a maré crescente de jornalistas, de "blogueiros" e de comunicadores, em todos os gêneros. As empresas anônimas de inteligência coletiva no Wikipedia empalidecem o prestígio do autor, do intelectualfonte-de-conhecimento.

A acumulação do saber parece ser suficiente para a cooperação bem regulada entre uma multidão de especialistas. A memória comum em rede se apresenta como um canal de difusão de grande eficácia. Em resumo, a figura - como a função - do intelectual estaria ligada à era das comunicações centralizadas como os meios impressos, o rádio ou a televisão, e declinaria na era das mídias transversais, nas quais cada um pode ser ao mesmo tempo receptor e emissor para um vasto público. O intelectual parece solúvel na "blogosfera". Não haveria mais do que pesquisadores especializados, transmissores de conhecimento, a serviço da economia da informação, e cidadãos capazes não apenas de votar, mas ainda de 
participar do debate na web. Apenas as pessoas expressamente eleitas ou nomeadas, os porta-vozes auto-proclamados, perdem seu emprego, já que cada um pode ter a palavra no novo espaço público. Com o desenvolvimento das atividades com alto valor agregado, o crescimento da educação superior e a extensão de uma rede interativa universal de comunicação, ampliada pela informática, o horizonte histórico deixa brecha para uma sociedade mundial do saber na qual o julgamento crítico é, de forma massiva, distribuído.

\section{0 intelecto}

Mas existe uma outra definição de intelectual, mais universal, e segundo a qual a responsabilidade, longe de se apagar com uma de funções cultural e historicamente datadas, toma hoje, ao contrário, uma amplitude nova. Comecemos por examinar a palavra "intelectual". Significa, etimologicamente falando, "o que se reporta ao intelecto". De acordo com esse sentido original, a função do intelectual é, pois, o estudo e o cultivo do intelecto.

Mas o que é o intelecto? O "intelecto", da forma que utilizo em francês, vem da tradição latina de um conceito aristotélico: o nós, que pode ser definido como a função cognitiva que distingue a espécie humana das outras espécies animais. Assim, definido a partir da natureza humana, a função do intelectual é universal, ou seja trans-histórica e transcultural. É preciso destacar que o intelectual não se distingue por sua inteligência: generalizando, da forma como eu estou fazendo aqui, todos os seres humanos são igualmente inteligentes, ou seja, todos têm uma mesma participação no intelecto, já que é essa participação que define, simplesmente, o fato de pertencer a uma mesma espécie. O intelectual, pois, não se distingue por sua potência ou pela intensidade de sua atividade intelectual, mas pelo $o b$ jeto desta atividade. O livro de Aristóteles sobre a alma, livro no qual o intelecto (o "nós") é definido e analisado, é, sem dúvida, um dos textos mais lidos, comentados e estudados na história das filosofias grega, latina, judia, muçulmana e cristã. Para Aristóteles, a alma é a "forma" do corpo. Aqui, a forma não significa só a aparência visual ou o volume geométrico do corpo, mas o conjunto das funções que atualizam seu potencial de atividade. A alma e o corpo se encontram em uma relação dialética na qual a atualização é uma transição da alma ao corpo. Aristóteles distingue três tipos de almas, ou seja, três grandes gêneros de funções biológicas, todas presentes no ser humano. A alma vegetativa, que corresponde, grosso modo, às funções de alimentação, reprodução, crescimento e declínio que também se encontram tanto nas plantas quanto nos animais; a alma animal, ou sensitiva, que corresponde às atividades de sensação e de motricidade que só se encontram nos animais (como a sensação comporta o prazer e a dor e a motricidade é levada em direção ao prazer e repudiada pela dor, o desejo faz, evidentemente, parte da alma animal). A imaginação, capacidade de produzir imagens a partir das sensações e lembranças das sensações, é, também, uma das funções dessa alma sensitiva. Por último, a alma intelectiva, que corresponde às funções de significação ou de tratamento dos símbolos, próprios da espécie humana, excluindo os outros animais. A vida intelectual recobre o conjunto das atividades simbólicas ou culturais. Esta vida intelectual se desdobra em universos de estruturas significantes: produção e metamorfoses de formas simbólicas, correspondências de formas de um sistema de signos a outro...

A hierarquia aristotélica das almas pode ser vista como a hierarquia dos níveis de codificação e de tratamento da informação explicitada pelos sistemas das ciências contemporâneas. A física estuda o nível de codificação e de tratamento energético e particular da informação. A química se ocupa de sua codificação e de suas transformações moleculares. O nível de codificação celular da informação é próprio de todos os seres vivos e corresponde, grosso modo, à alma vegetativa de Aristóteles (o que nós chamamos, às vezes: "o corpo"). A neurologia se ocupa da codificação nevrálgica da informação do mundo fenomenal, ou da cognição sensório-motriz, própria dos animais e que corresponde, evidentemente, à alma animal ou sensitiva de Aristóteles. Entre a codificação neurológica e a simbólica, pode-se intercalar uma codificação emocional, particularmente desenvolvida nos mamíferos, e que se liga a equilíbrios complexos entre comportamentos sociais e hormonais e neurotransmissores. Este universo de tratamento socioafetivos da informação é, especialmente, estudado pelos etólogos. Finalmente, a codificação e o tratamento simbólico da informação, do qual se ocupam as artes e as ciências do homem, correspondem à alma intelectiva, ou ao "nós" aristotélico. Exprimese, tradicionalmente, a diferença específica do humano dizendo que ele é um animal dotado de linguagem, de razão ou de "logos". Mas insisto, aqui, sobre o fato de que o intelecto não pode ser reduzido apenas ao tratamento da codificação lingüística da informação, pois trata de todas as formas de codificação simbólica própria da espécie humana. Os símbolos, que são o objeto das operações intelectuais, podem ser musicais, icônicos, coreográficos, matemáticos, técnicos, religiosos, econômicos, jurídicos, culinários, vestimentários, sexuais etc. O conjunto das instituições culturais, ou seja, o conjunto dos sistemas de codificação e dos programas de tratamento simbólicos pertencem às manifestações do intelecto. De resto, na própria codificação lingüística, a cognição intelectual não é limitada à função puramente lógica, dedutiva, indutiva, abdutiva ou racionalizante, em geral, ou seja, ela não exclui qualquer uso efetivo ou possível dos símbolos lingüísticos, qualquer "jogo de linguagem". 


\section{A dialética intelectual}

Aristóteles analisa a vida do intelecto em três momentos interdependentes. O primeiro momento, que Aristóteles chama de o intelecto possível, ou passivo, é um universo de inteligibilidade virtual que o fundador do Liceu compara a uma capacidade ou a um órgão de "visão" intelectual.

O segundo momento, que Aristóteles chama de $o$ intelecto agente, é a causa eficiente da cognição simbólica. O intelecto agente é comparado por ele a uma luz intelectual capaz de excitar a visão simbólica. Considera este intelecto "separado" do restante da alma. O regozijo primordial do intelecto agente é, na verdade, segundo o filósofo, independente das sensações e das imagens particulares oriundas da alma sensitiva, da mesma forma que é independente da receptividade do intelecto possível.

$\mathrm{O}$ terceiro momento, que Aristóteles chama de intelecção, ou o inteligível em ato, resulta da atualização do intelecto possível pelo intelecto agente. É o processo cognitivo efetivo que nasce da onda de luz intelectual e do órgão sensível a essa onda.

Ainda conforme a dialética noética proposta por Aristóteles, eu irei, agora, introduzir livremente certas considerações que não lhe pertencem.

Eu relaciono o intelecto à capacidade humana geral de visar, de dotar de intenção ou de significar objetos intelectuais, abstrações ou conceitos. Até aqui, eu não me distancio de Aristóteles. A diferença que eu introduzo vem pelo fato de que, contrariamente ao filósofo, não vejo o intelecto agente como um momento da vida "separado" da experiência variável e do mundo sensível. Eu considero, na verdade, que são as comunidades humanas reais, situadas no tempo e no espaço físicos, que conduzem o intelecto agente (a capacidade universal de significar ou de simbolizar). Esta interpretação "humanista" do intelecto agente se opõe a uma tradição multissecular de interpretação que insiste, pelo contrário, sobre seu caráter "separado". Esta tradição separatista passa, em particular, pela escola neo-platônica (Plotin, especialmente) e por filósofos como Avicenne, Averroès, Maimonide e numerosos teólogos latinos medievais. Segundo esta leitura do intelecto agente como separado, a luz intelectual vem "de cima", de uma região do ser que não é submetida à impermanência terrestre e que encontra sua fonte última no Pai das Luzes. Mas a interpretação medieval que faz do intelecto agente uma causa transcendente e a interpretação contemporânea que o relaciona a uma atitude biológica dos cérebros humanos sobre os símbolos têm alguma coisa, na essência, em comum: a dialética entre a unidade ou a universalidade da potência de significar e a grande quantidade virtualmente infinita das significações. Esta dialética do uno e do múltiplo é, particularmente, bem expressa na citação de Dante, extraída de seu tratado sobre a monarquia $(\mathrm{I}, 3)$ :
O termo extremo proposto à potência da humanidade é a potência, ou virtude, intelectiva. E como esta potência não pode, de repente, se reduzir inteiramente em ato através de um só homem ou de uma comunidade particular, é necessário que reine no gênero humano uma grande variedade através da qual ocorra esta potência inteira [...]. E Averrhoes está de acordo com esta sentença, conforme comentário sobre os livros da alma.

Após o intelecto agente emissor da "luz" intelectual, examinemos, agora, o intelecto possível, órgão da "visão", ou da compreensão simbólica. Grande parte das interpretações de Aristóteles remete o intelecto possível a uma capacidade individual. Existem, no entanto, certos autores, como Averroès, que vêem nele um órgão que dispensa as formas intelectuais comuns a toda a humanidade. As diferenças evidentes entre as representações e as operações cognitivas dos indivíduos viriam das diferentes maneiras com as quais eles "captam" as formas oriundas do intelecto comum. De minha parte, proponho uma interpretação intermediária entre o intelecto possível comum a toda a humanidade e o intelecto possível puramente individual. A razão pela qual eu não atribuo ao intelecto possível apenas o indivíduo é que as operações de cognição simbólica da qual ele é a matriz são, amplamente, condicionadas pelas tecnologias intelectuais (línguas, escrituras, mídia...), pela memória disponível e pelas ocasiões institucionais e sociais de pensar fornecidas pela sociedade onde ele vive. O intelecto possível depende de uma máquina abstrata de codificação e de tratamento simbólico que se pode designar, se for o caso, pelo termo de matriz cultural. Esta matriz organiza uma "ligação" entre, de um lado, a cultura no sentido levi-straussiano do termo, ou seja, uma correspondência mais ou menos estável e bem regulada dos sistemas simbólicos (a codificação), e, de outro lado, uma coleção de mídia, no sentido macluhaniano do termo, ou seja, um conjunto mais ou menos coerente de dispositivos de apoio e de transformação dos símbolos (o tratamento). Assim definido como "ligação" entre sistemas de codificação e sistemas de tratamento, o intelecto possível representa uma espécie de tema transcendental histórico, situado e tecnicamente equipado, próprio de uma comunidade humana. Trata-se, em outros termos, de um metaparadigma ou de uma episteme complexa, incluindo o meio ambiente sócio-técnico que condiciona um espaço abstrato de coordenações possíveis entre atividades simbólicas.

$\mathrm{O}$ intelecto agente, a saber $a$ atitude de significar, própria da espécie humana, é único, universal e manifestado por todas as comunidades humanas, o que não se verifica em relação ao intelecto possível: não apenas uma faculdade de linguagem, mas línguas múltiplas; não apenas uma potência construto- 
ra, mas múltiplas técnicas; não só uma disposição aos jogos sociais complexos, mas uma grande variedade de instituições. As combinatórias de signos não só lingüísticos, da mesma forma que os sistemas e os programas de registro, de comunicação e de tratamento dos símbolos, diferem segundo o tempo e os lugares. É, justamente, este descompasso entre os intelectuais possíveis e o intelectual agente que origina a variabilidade e, de um só golpe, a evolução cultural.

A potência de significar própria da espécie humana só pode se exprimir atualizando estes ecossistemas de maquinarias simbólicas que são as matrizes culturais. Para ser operatório, o intelecto agente deve ativar, aqui e agora, um intelecto possível particular, fisicamente inscrito no sistema nervoso dos integrantes de sua comunidade, como na mídia que reúne esta comunidade. A encarnação distribuída da maquinaria simbólica tem por efeito condicionar e colocar em relação regrada os atos de intelecção pessoais para a produção de uma inteligência coletiva. É assim que o tratamento dos símbolos se encontra socialmente coordenado. Contrariamente à inteligência coletiva dos outros animais sociais, a inteligência coletiva propriamente humana não emerge, então, exclusivamente das trocas de moléculas, de sensações e de emoções entre organismos; ela significa, igualmente, uma economia simbólica regrada pelas matrizes culturais.

\section{0 papel dos intelectuais em geral}

O intelecto agente, como vimos, é trazido pelas comunidades humanas em seu conjunto. O intelecto possível se apresenta como o conjunto dos instrumentos simbólicos - o organon - com os quais desempenha o intelecto agente. A potência de significar ao ser coagida ou condicionada por este organon simbólico faz com que o intelecto agente "desempenhe" a sinfonia atual da inteligência coletiva.

A interação do intelecto agente e do intelecto possível produz uma inteligência atual. Este jogo de inteligência coletiva atual é, por natureza, social: atravessa e integra o conjunto dos membros de uma comunidade. Ao ser esboçada a dialética da cognição simbólica, pergunta-se: qual é o papel que desempenham os intelectuais? No modelo que proponho, os intelectuais são os "luthiers" (n.t.espécie de artesão) que produzem, mantêm e aperfeiçoam o intelecto possível (a instrumentação simbólica) das comunidades pelas quais eles trabalham. Sua função não é, pois, pensar (todo mundo pensa), mas pensar o intelecto, estudar a economia da informação simbólica, compreender o funcionamento das máquinas de codificação e produzir o sentido que torna a intelecção pessoal e coletiva possível, além de propor, eventualmente, diagnósticos e orientações de evolução. De modo mais específico, os intelectuais mantêm as canalizações abstratas do fluxo simbólico: os números e as letras, as imagens e os ideogramas; os diagramas e os gráficos; as grandes narrativas e os rituais; as teorias; as classificações e as cosmologias; sistemas de escritura das idéias e os números; "organons" lógicos e matemáticos; moedas, bancos e contabilidades; organizações da memória e combinatórias de símbolos; sistemas de música e arquiteturas de ícones; gramáticas, dialéticas e retóricas; geometrias e cartografia; regras de leitura e de interpretação de todos os gêneros: todas estas tecnologias intelectuais, com o corpo de "savoir-faire" que permite aperfeiçoamento, foram inventadas, sustentadas e desenvolvidas pelos intelectuais.

\section{A partir do momento em que uma informação se encontra na rede, ela está, virtualmente, em todo lugar.}

Vários grupos diferentes preencheram a função que consiste em conter os recuos e organizar os avanços do intelecto possível. Bem antes dos intelectuais críticos dos séculos XIX e XX, os padres egípcios, os escribas mesopotâmicos, os filósofos taoístas, os brâmanes e teósofos meditantes da Índia, os monges budistas através das culturas asiáticas e, recentemente, ocidentais, os talmudistas e doutores da lei hebraica, os filósofos e matemáticos gregos, os teósofos persas e andaluzes do império muçulmano, os monges teólogos da Idade Média latina que inventaram a universidade, os impressores humanistas e a Renascença européia, os sábios que estão na origem da revolução das ciências experimentais, os arautos da filosofia das Luzes, cada um a seu modo, foram os observadores da unidade do intelecto e dos especialistas inventivos das tecnologias e disciplinas que permitem aumentar sua potência. E ainda mais cedo na aventura humana, nas culturas orais das tribos nômades, havia os "griots", bardos e xamãs encarregados da memória dos clãs e da comunicação com o espírito.

Nossa geração foi alimentada pelas mais recentes descobertas da história e dos estudos transculturais. Ela foi elevada aos universos antropológicos na mesma medida da importância determinante da mídia e dos signos. Os sucessos da informática advertiram a potência intelectual conferida às comunidades humanas pelos utensílios de tratamento da informação. Ela é, pois, capaz de reconhecer sob formas diversas, ao menos retrospectivamente, a atividade universal que consiste em conservar e amplificar o intelecto possível. Da mesma forma que existe alguma coisa como uma medicina em todas as culturas, mesmo se cada cultura tenha sua própria tradição médica, existe algo como um cuidado universal do intelecto, de sua saúde, de sua fecundidade simbóli- 
ca. Na minha opinião, os intelectuais de hoje são os especialistas das ciências e técnicas da informação, os pesquisadores em ciências humanas e sociais e em geral - os grupos profissionais, ou outros, que se encarregam da gestão da memória coletiva, ou seja, da transmissão e renovação das tradições culturais.

Em suma, o intelectual não se contenta em utilizar as tecnologias disponíveis da inteligência coletiva de sua cultura, mas as observa, as compreende, as cultiva e as aperfeiçoa. É para o intelectual, principalmente, que o meio é a mensagem: não apenas o texto, mas a combinatória dos caracteres de onde ele emerge e que permite estender o sentido; não apenas a biblioteca, mas também a indústria gráfica e a edição que produz, além dos sistemas de fichas e de classificações que permitem sua exploração; não apenas as quantidades, mas também os sistemas métricos as normatizam, e as funções matemáticas que as transformam; não apenas a voz que fala ao telefone, mas também o novo espaço-tempo da experiência humana produzido pela rede telefônica. $\mathrm{O}$ intelectual trabalha pelo aumento das possibilidades da inteligência coletiva de sua cultura, focalizando, de preferência, os sistemas gerais de codificação e de tratamento simbólico da informação. Seu trabalho se concentra nestes elementos porque são eles que definem as operações possíveis da cognição propriamente humana.

\section{A nova matriz cultural}

Com qual situação os intelectuais contemporâneos são confrontados? Resumamos, aqui, os dados principais que dizem respeito à nova camada universal de codificação e de tratamento da informação simbólica que se articula, a partir de agora, junto à multiplicidade das matrizes culturais locais. Primeiramente, os programas de informatização dos circuitos eletrônicos colocam a nossa disposição os automatismos manipuladores de símbolos. A disponibilidade destes automatismos data de meio século em alguns centros e só se acha à mão do público dos países ricos há cerca de 30 anos: por pouco uma geração nos separa do nascimento da informática pessoal. Os automatismos manipuladores de símbolos são praticamente capazes de resolver todas as operações formalmente definíveis não importando o tipo de informação, desde que esta informação tenha sido codificada de forma digital. Os manipuladores automáticos de símbolos nos servem para escrever, editar e ler os textos, produzir e ver imagens, produzir e escutar música, gerir nossas finanças, nossa economia, nossos atos administrativos e, cada vez mais, estruturar, de forma integrada, nosso conhecimento organizacional. A informática aumenta, diariamente, nossas capacidades pessoal e coletiva de memória, de simulação, de raciocínio e de comunicação.

Em segundo lugar, a maioria da memória cultural, de curto ou longo prazo (da mídia às bibliote- cas), é digitalizada ou em via de digitalização, qualquer que seja sua especialidade (científica, artística ou outra) e qualquer que seja a forma sob a qual esta informação simbólica é representada (textos, imagens, sons ou programas). A digitalização permite uma potência quantitativa de tratamento e uma sofisticação de transformação e de análise automática em uma escala ainda desconhecida há meio século.

Em terceiro lugar, tanto as memórias digitalizadas quanto os manipuladores automáticos de símbolos que são os programas informatizados estão em via de interconexão acelerada em uma rede universal de comunicação: o ciberespaço. A partir do momento em que uma informação se encontra na rede, ela está, virtualmente, em todo lugar. Os documentos digitais fazem parte, virtualmente, de um hiperdocumento dinâmico universal, alimentado, percorrido e transformado pelo conjunto das instituições e dos indivíduos que compartilham o ciberespaço. Mesmo se a interconexão dos computadores pelas linhas telefônicas começou no ínicio dos anos 1970, foi só a partir dos anos 1990 - com a web - que passou a se generalizar e conhecer um uso massivo. Trata-se, então, de um acontecimento forte e recente (menos de uma geração) na escala da evolução cultural. Se multiplicarmos a potência de manipulação automática e a capacidade de colaboração dos agentes de programação pela ubiqüidade e a interconexão do ciberespaço se obtém a capacidade de tratamento do novo intelecto possível. Nada permite estimar que a nova matriz cultural, cuja base técnica acaba de ser desenhada em linhas gerais, se encontre em um estado definitivo. A codificação digital, sem dúvida fundamental, é só a base física de uma imensa pirâmidade de códigos, normas, linguagens e interfaces superpostas que ligam os circuitos eletrônicos (e, acima de tudo, óticos ou bioeletrônicos) aos usuários humanos. Ora, tudo leva a crer que este " mil-folhas" de transcodificação está longe de seu final.

De fato, obstáculos sérios impedem a inteligência coletiva de explorar plenamente as potencialidades da nova camada universal de tratamento simbólico. Estes obstáculos são:

\section{a. a multiplicidade das línguas culturais;}

b. a incompatibilidade mútua e a falta de adaptação dos numerosos sistemas de indexação e de catálogo herdados da era da indústria gráfica (que não foram concebidos para o uso da interconexão e para a potência de cálculo do ciberespaço);

c. a multiplicidade das ontologias, taxonomias, terminologias e classificações;

d. as dificuldades encontradas pela engenharia da informática ao se levar em conta a significação dos documentos no meio de métodos gerais; 
e. a ausência de transparência dos métodos utilizados pelos motores de pesquisa comercial contemporânea e sua relativa ineficácia a partir do momento em que a tarefa que lhe é confiada é pouco complexa.

Este conjunto de obstáculos para o desenvolvimento da inteligência coletiva com suporte digitalizado é conhecido sob o nome de "problema de interoperacionalidade semântico". Como se vê, a principal dificuldade se situa na codificação e na organização semântica da informação (as estruturas de representação formal do sentido) e não na codificação física (a linguagem binária ordenada pelos circuitos eletrônicos).

Dito de outra forma, a informação simbólica e seus agentes de tratamento automático estão em via de uma unificação material em uma memória virtual comum ao conjunto da humanidade, mas como as barreiras, obstáculos e incompatibilidades semânticos foram só parcialmente superados, hoje, o crescimento da inteligência coletiva, mesmo que destacado, permanece bem aquém do que poderia ser. Mas isso causa alguma surpresa? A imensa maioria dos sistemas de codificação do sentido, hoje, foi inventada bem antes da existência do ciberespaço. E o próprio ciberespaço só existe para o público mundial há menos de uma geração. A nova matriz cultural está inacabada. Os intelectuais do século XXI se confrontam, pois, com o problema de inventar, adaptar e aperfeiçoar uma nova geração de sistemas simbólicos que seja o diapasão da potência de tratamento disponível, daqui para frente.

Eu me refiro aos intelectuais como os promotores do intelecto em sua integralidade viva, e não " puros" engenheiros apenas especialistas dos circuitos eletrônicos e da lógica formal. Paradoxalmente, no momento em que se confirma o crescimento e a diversificação dos usos do ciberespaço, a engenharia dos programas pena em renovar seus conceitos. Depois de uma fase de grande criatividade no fim do século $X X$, a inteligência artificial parece ter perdido sua força e a web " semântica " (na realidade, como veremos abaixo, uma web lógica), lançada há mais de dez anos, não suscita mais o progresso esperado, apesar de seu refinamento técnico. Ora, o grosso da memória cultural acumulada nos arquivos, bibliotecas e museus esbarra nas redes digitais, enquanto as questões ligadas à diversidade cultural e lingüística passam ao primeiro plano da gestão do ciberespaço. Assim, os problemas relativos à complexidade do sentido e de sua interpretação (que estão entre os objetos clássicos das ciências humanas e é uma das principais preocupações dos intelectuais) não podem mais ser evitados pelos arquitetos do novo espaço de comunicação mundial. A iniciativa da construção do ciberespaço poderia, então, passar - ao menos parcialmente - aos intelectuais treinados nas ciências do homem e da sociedade.

Além de tudo, a lógica incorporada nos progra- mas informatizados e nos circuitos eletrônicos começou por ser formalizada pelos filósofos, entre os quais Aristóteles, em primeiro lugar. Por que os refinamentos da semântica (mais sutis ainda que os da lógica) não poderiam ser formalizados? E quem melhor do que os pesquisadores em ciências são capazes de encarar esta empreitada?

\section{As camadas de endereçamento da memória digital}

Eu irei, agora, tentar descrever o estado da arte onde se edifica a nova matriz cultural. A estrutura fundamental da memória coletiva em rede pode ser analisada em uma série articulada de camadas de endereçamento. A primeira camada (a dos sistemas de exploração dos computadores) endereça os bits elementares da informação no nível físico dos circuitos e dos suportes materiais. A segunda camada (a da Internet) endereça os servidores da informação para o ciberespaço. A terceira (a da web) endereça as páginas dos documentos. Minha hipótese é que os intelectuais do século XXI devem tomar a iniciativa no sentido de instaurar uma quarta camada (a da noosfera, ou esfera do "nós") endereçando os conceitos. Como se pode constatar, estas diferentes camadas foram desenvolvidas, sucessivamente, no tempo, e cada uma delas precisa da existência das precedentes para funcionar.

\section{PRIMEIRA CAMADA (ENDEREÇAMENTO DO BITS)}

Em relação aos computadores que compõem os laços do ciberespaço, o sistema local de endereçamento dos bits de informação é gerado de forma descentralizada por diversos sistemas de exploração informatizada (tais como Unix ou Windows) e utilizado por programas de aplicação. Baseado neste endereçamento dos dados e dos programas na memória do computador, o desenvolvimento da informática nos anos 1950 do século XX criou as condições técnicas de um aumento considerável dos tratamentos aritmético e lógico da informação. Em geral, todo o edifício simbólico do ciberespaço repousa na lógica matemática e na codificação binária das informações.

\section{SEGUNDA CAMADA (ENDEREÇAMENTO DOS SERVIDORES)}

Em relação à rede das redes, cada servidor tem um "endereço" atribuído segundo o protocolo universal da Internet. Os endereços IP (Internet Protocol) são explorados pelo sistema de comutação da informação que opera a Internet. O desenvolvimento da Internet nos anos 1980 corresponde à eclosão da informatização pessoal, ao crescimento das comunidades virtuais e ao início da convergência da mídia e das telecomunicações no universo digital. A existência de programas de aplicações (tratamento de texto, ferramentas de desenho e de tratamento de imagem etc.), da mesma forma que a atualização das interfaces de comunicação intuitiva (ícones, mouses, janelas, etc.) com os usuários, desempenhou, 
igualmente, um papel importante nesta segunda camada do ciberespaço.

\section{TERCEIRA CAMADA (ENDEREÇAMENTO DAS PÁGINAS)}

Em relação ao World Wide Web, as páginas dos documentos têm, por sua vez, um endereço universal segundo o sistema também universal do URL (Uniform Resource Locator) e os links entre os documentos são tratados pela norma HTTP (HyperText Transfer Protocol). Os endereços na web e os links de hipertextos são explorados pelos motores de pesquisa e pelos navegadores. A generalização da web a partir de 1995 facilitou o aparecimento de uma esfera pública que é, hoje, enriquecida pelo o que se chama "web semântica". Mas a palavra "semântica" é, sem dúvida, utilizada, aqui, de forma abusiva, pois este novo desenvolvimento da web propõe, essencialmente, normas de codificação lógica das informações. As principais ferramentas simbólicas da web são:

a. XML (eXtended Mark-up Language), derivado da linguagem SGML (Standard Generalized Markup Language) de Charles Goldfarb, que permite descrever de modo universal a estrutura das bases de dados;

b. RDF (Ressource Description Framework), que permite catalogar os dados da web;

c. OWL (Ontology Web Language), que permite descrever as ontologias, ou seja, as estruturas conceituais dos diversos domínios de conhecimentos que podem servir de base às inferências automáticas.

Esta aparelhagem de marcadores tem por principal função favorecer a automatização dos tratamentos na pesquisa de dados e na execução das operações confiadas aos programas. Mas o problema da interoperacionalidade semântica não foi resolvido pela web "semântica" no que diz respeito aos métodos gerais, e isso, pelo menos, por duas razões que irei examinar sucessivamente: a incompatibilidade das numerosas ontologias e o arbitrário da anotação dos conceitos em línguas naturais.

a. A incompatibilidade das ontologias: é verdade que as ontologias permitem reparar, automaticamente, as relações entre conceitos, mas (a) os conceitos são expressos, na maior parte do tempo, em uma língua natural e (b) os milhares de ontologias hoje disponíveis são incompatíveis umas em relação às outras. $\mathrm{O}$ reconhecimento automático das relações entre conceitos é, pois, limitado, na maioria dos casos, a uma única ontologia em uma mesma língua.

b. O arbitrário da anotação de conceitos em línguas naturais: mesmo se XML, RDF et OWL formali- zam as relações entre conceitos na linguagem universal e neutra da lógica, os próprios conceitos são anotados por palavras ou abreviações em línguas naturais. Ora (a), existem milhares de línguas naturais diferentes, (b) no interior de cada uma dessas línguas, as palavras podem ter vários sentidos e (c) o mesmo sentido pode ser expresso por diferentes palavras, sem falar (d) nas trocas de sentido devido às variações de contextos e de pontos de vista. Mesmo que os links entre as etiquetas lógicas do XML, RDF e OWL sejam calculáveis, os canais de caracteres que elas assinalam permanecem sendo códigos arbitrários do ponto de vista da computação semântica.

A título de comparação, o sistema de anotação dos números por posição (que seja em base dez, em base dois ou em outra) permite uma interpretação universal e unívoca do sentido de cada número e do lugar ocupado por cada número na expressão. $\mathrm{O}$ conceito correspondente à seqüência dos números pode, pois, ser deduzido automaticamente desta seqüência. Em contrapartida, a anotação alfabética das palavras em línguas naturais chega aos códigos arbitrários - os canais de caracteres - que é sempre possível comparar ou ligar a outros canais de caracteres, mas sem que os caracteres ou sua disposição possam ser interpretados por si mesmos. Os símbolos elementares representam, aqui, os sons e não os elementos de significação. Em resumo, para os automatismos manipuladores de símbolos, os números anotados em uma ideografia indo-árabe estão diretamente acessíveis, enquanto as línguas naturais anotadas em caracteres alfabéticos são semanticamente opacas.

\section{0 projeto de inteligência possível: a inteligência possível, quarta camada do ciberespaço}

A análise detalhada da terceira camada do ciberespaço (a web) era necessária para justificar a construção detalhada de uma quarta camada, propriamente semântica. A principal função desta quarta camada, que chamo inteligência possível, é endereçar os conceitos, as idéias ou as noções e, conseqüentemente, indexar os documentos pelos conteúdos, independentemente das línguas naturais nas quais estes documentos foram produzidos e os sistemas de classificação particulares que permitem hoje explorá-los. Em 2007, esta quarta camada do ciberespaço não existe e, até onde sei, o projeto de sua construção só é defendido pela rede internacional da Cátedra de pesquisa em inteligência coletiva da Universidade de Ottawa. É preciso, então, que eu apresente as grandes linhas do projeto de inteligência possível antes de entrar nos detalhes de seu funcionamento. afAMECOS 